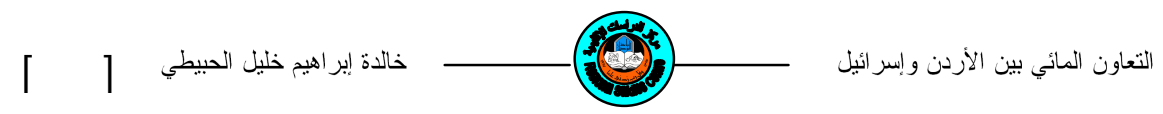

العلاهات العسكريه السعوديه الامريكيه: واعدة الظهران الجويه اتمودجا

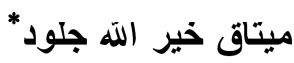

$$
\text { ملخص البحث }
$$

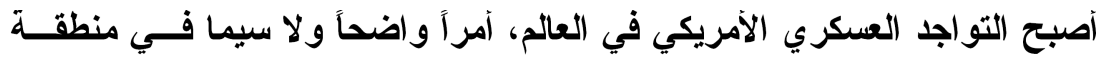

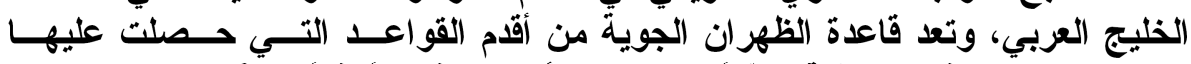

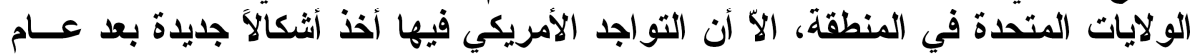

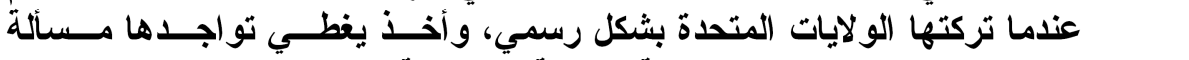

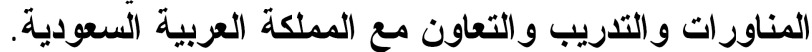

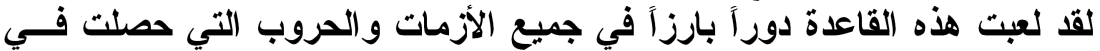

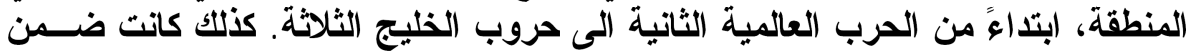
الاستر اتيجية الأمريكية وجزء العزية فاعل في التكتيكات الأمريكية في منطقة الخليج العربي.

\title{
مقدمه
}

تعد القواعد الاجنبيه في الدول العربيهه ظاهرة من المقيد التوفف عندها، للزيــادة في وهم الإستقطابات السياسيه، وإستراتيجيات الدول العظمى وطرق التعامل العربيه مع هاه الإستر اتيجيات ومدى الممانعه والاستجابه، وي اطار العلاهات العسكريه. إن تربع الولايات المتحدة على عرش الدول العظمى، وإنقر ادها بالعالم مند اكتر من عقد من الزمنه يقرض على جميع المؤسسات والاوراد التووف عند سياسه هله الدوله، لتهيئه ارضيه وويه للتصدي لها ووق التوابت الوطنيه و القوميـهـه والــدواع عـن الإرث الديني والحضاري. ووفق هده الروئه فإن التواجد الامريكي في منطقه الخليج العربـي يعد ارضا خصبهه للوفوف على مقاصد ها التواجد وكيقيه تعامل دول الخلـيج معسهـ. جاءت هده المحاوله لتسليط الضوء على فاعدة الظهران الجويه وي المملكــهـ العربيـهـه السعوديه من حيث النشاة ودورها في الاحداث الإقليميه و الاوليه، بوصفها صفحه مسن 
صفحات التعاون السعودي الامريكي في المجال العسكري، ووـــ تتـــاول البحــث عــدة

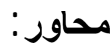
1 - القواعد والتسهيلات المنوحه للولايات المتحدة في منطقه الخليج العربي. r - نشاة فاعدة الظهر ان الجويه. r - دور القاعدة في المنظومه العسكريه لمنطقه الخليج العربي.

1 - القواعد والتسهيلات الممنوحه للولايات المتحدة وي منطقه الخليج

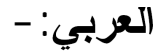

عتدما وضعت الحرب العالميه التانيه اوزارها، بلات الولايــات المتحـــة ببنـــاء منظومـه من القواعد غطت اتحاء مختلفه من العالم لتتقيل سياسه الاحتواء ضــــ المــــ السويتيه ووراته مجد المملكه المتحدة'. ووي عام 1979 طرحت تساؤلات في الكونكرس مفادها؛ هل يتطلب الامن القومي الامريكي الاحتقاظ بِهده الاعداد الكبيرة من القواعد والعكر خــارج حــدود الولايــات المتحدة ؛ وحصل تقليص لحجم القواعد خارج حدود الولايات المتحدة، وعلى الرغم من

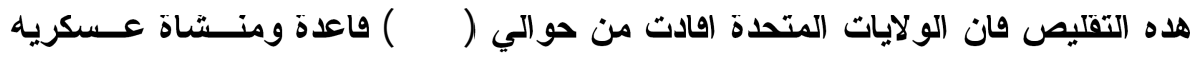

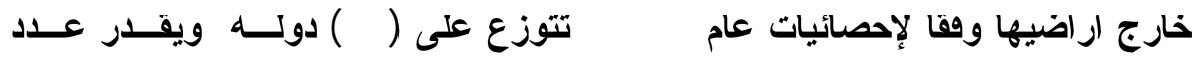

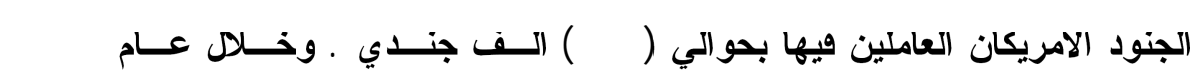
اصبحت الولايات المتحدة تمتلك اكتر من ( . - ع) صاعدة ومنشاة عسكريه في اكتر مسن دوله (عV) وبالنسبه لمنطقه الخليج العربي هالولايات المتحدة تقيل من عدة وواعد ومر افئ في دول الخليج ياتي وي مقدتها هاعدة الظهزان الجويه، ومرها الجقير في البحرين إضــاهيه

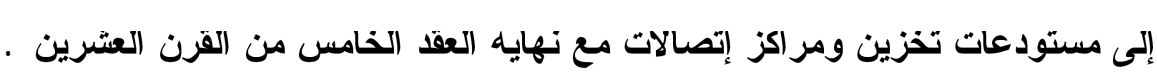
وفي حزيران/يونيو I9Vr وصف جوزيف سـسكو .Joseph S. مسساعد وزيسر الخارجيه الامريكيه، منطقه الخليج باتها منطقه للولايات المتحدة ويها مصالح سياسـيه ونيه

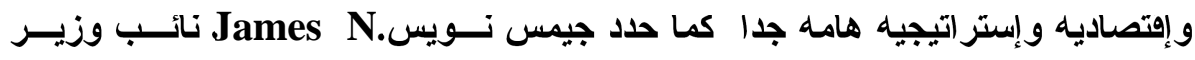
الدهاع الامريكي مصالح الولايات المتحدة في الخليج، بإحتو اء الـسوفيت، و إســتمراريه 
الحصول على النفط، وتامين حركه السفن والطائر ات الامريكيه في المنطقه ولفهم حجم ومستوى التسهيلات والقواعد الممنوحه للولايات المتحدة من فِبل دول مجلس التعاون لاول الخليج العربيهه نورد إحصائيه للمنشات التي إســفادت الولايــات

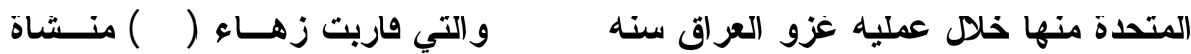
وهي كالآي: I - عمان: فاعدة مصيرة الجويه، قاعدة المسنه الجويه، ميناء قابوس، مطار الـسيب الدولي، قاعدة التمريات الجويه و ميناء صلاده. م - الإمارات: قاعدة الظقرة الجويه، محطه صياته ووفود السفن (القجيـرة)، مطــر الفجيرة الدولي،ميناء جبل عليه ميناء زايل. ץ - وطر: صاعدة العديد، معكر سنوبي، مطار الدوحه الدوليه معسكر السيليه، فاعدة ام سعيد. ع - البحرين: واعدة إسناد انشطه بحريه (الجقير)، ميناء ســلمان، مطــار المحــرقه صاعدة الشيخ عيسى الجويه. 0 - الكويت: صاعدة احمد الجابر الجويه، فاعدة علي السالم الجويه، معسكر عريقجانه معكر الدوحه، جزيرة فليكا، مطار الكويت الدوليه ميناء الاحمدي 7. 7 - المملكه العربيه السعوديه: (1) واعدة الدمام البحريه: والتي انشات وهق طلب الحكومه الـسعوديه مسن الولايــات المتحدة للاغراض التجاريهه إلا ان بعض المتابعين يرون ان الولايات المتحدة إختــارت موفع الدمام ليكون فاعدة بحريه امريكيهاوالدي يعزز هلا القوله إن الدراســه الفتيـهـ

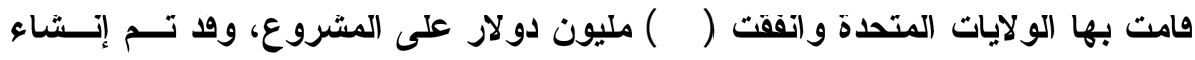
المرحله الاولى من القاعدة في ادار/مارس - 190.

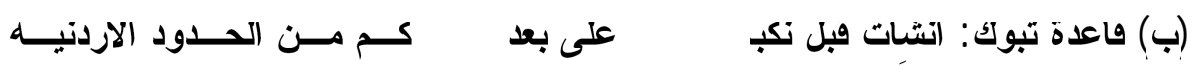


باشر اف الخبراء الامريكان.

(ج) هاعدة ابها (خميس مشيط): تقع على بعد . - 1 كم من حدود اليمن وضد بدا التقكير

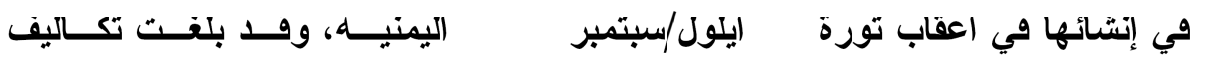

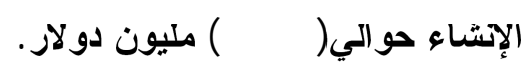
(د)(قاعدة الباطن: اعلن عن نيه إنشائها نهايه عام I9V في موقع مريب من الحـدود العز اويه (0) إضاهه إلى دلك هاعدة الظهران الجويه والتي نحن بصددها، ميناء الملك عبد العزيز (الامام)، قاعدة جدة الجويه، صاعدة الملك فه البحريه (جدة)، ميناء جدة، قاعدة الملك

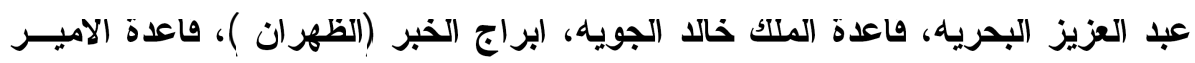

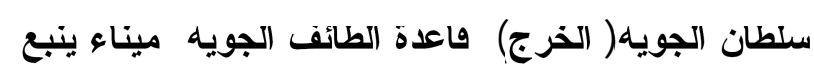
r - نشاة صاعدة الظهران الجويه

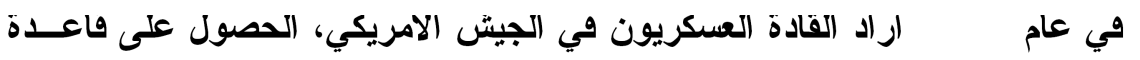

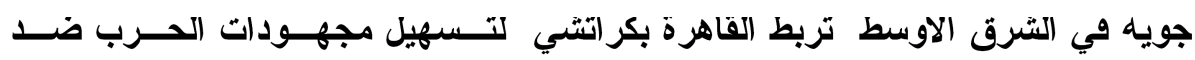

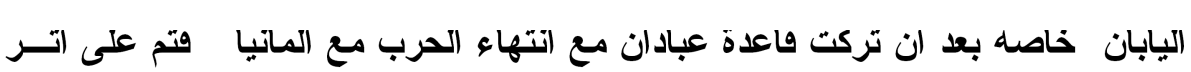
دلك إجراء دراسه سريه من فبل عسكريين امريكان ووفع الاختيار على منطقه الظهرانه

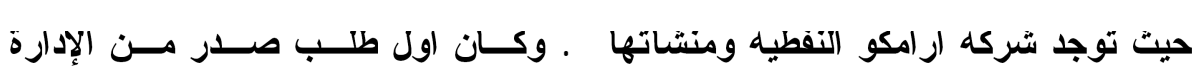

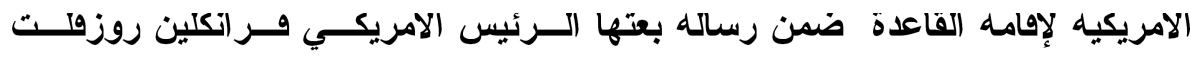

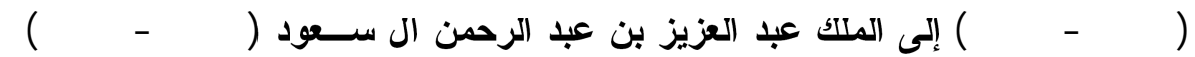
فابدى الملك تجاويه وي رساله جو ابيهه وعلى اتر دلك سارعت وزارة الحربيه الامريكيه إلى إرسال بعته لاراسه الجوانب الفنيه في إنشاء المهابط الخاصه بالطائرات والممرات

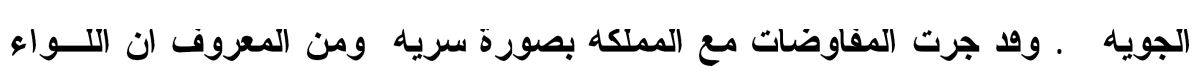
رالف رويس .Ralph R قائد ووات الولايات المتحدة في الثشرق الاوسط، فام في كانون

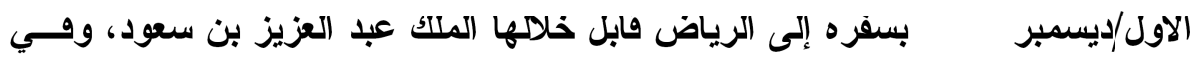

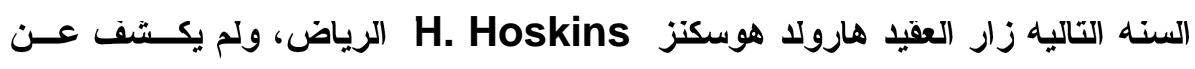




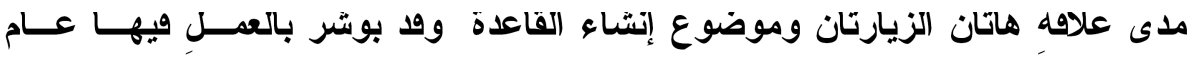
ع أباستخام موظقين عسكريين واسرى حرب إيطاليين عقب مراسلات بين المملكه

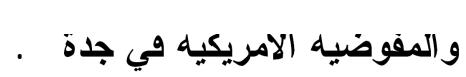

وفي شباط/عبراير 1980 التقى الرئيس الامريكي روزولت والملك عبد العزيز فـي منطقه السويسهيث اكل الرئيس الامريكي ان الدور الامريكي في المنطقه سيزداد مسن خلال هده القاعدة، لكن وهاة روزهت في نيسان/(بريل 190 اه وانتهاء الحرب العالميه

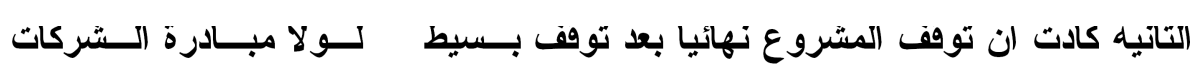
البتروليه وضغطها المتواصل على الكونكرسموالدي اوعز بلدره إلى اسـتئناف العــل

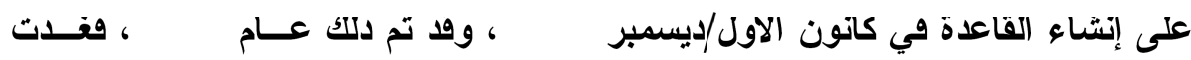

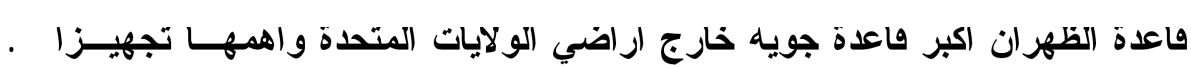
وفي rY حزيران/يونيو I9VV تم التويع رسميا على اتفايه استخدام القاعـدة لمــدة تلاث سنوات تسلم بعدها للحكومه السعودياه، وبللك وجلت اول منشاة عسكريه تستخدم من وبل الامريكان في منطقه الجزيرة العربيه 10.

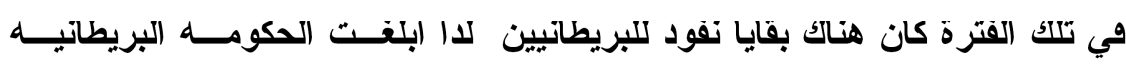
و الثنطن باتها ولقه من مساله إنشاء هاعدة الظهران خاصه بعد ان علم اتــهـ سيحـصل تعاون تجاري امريكي سعوديهمما سوف يخلق منافهه غير مسستحبه مـــع الــشركات البريطانيه العامله وي المنطقه وجاء الرد الامريكي بان التسهيلات التجاريه التي حصلت عليها الخطوط الجويه الامريكيه لن يكون من شنانها الإضرار بالمصالح البريطانيـهـ لان المطار السعودي سوف يكون مفتوحا امام جميع الخطوط الجويه الاجنبيهل 17. وبعد انتهاء امد الانقاويه الاولى الخاصه بالقاعدة جلدت هده الاتفاهيه عــام لمدة سنتين، وفي 11 حزيران/يونيو 1901 ووعت اتفاهيه جديدة بين وزير الخارجيـه Remond H. السعودي الامير ويصل وسفير الولايات المتحدة وي الملكه ريموند هير في جدة، ونصت الاتفافيه على عشرين هقرة، تستطيع الولايات المتحدة من خلاكه ان 


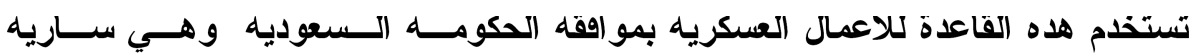
المفعول لمدة خمس سنواته إلا إدا ابلغ احد القريقين القريق الاخر في مدة سته اشهر

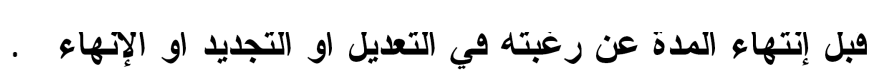

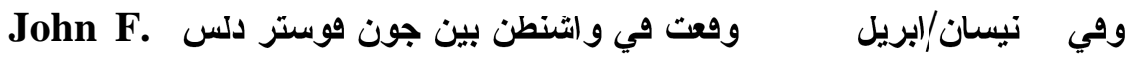
D. وزير الخارجيه للولايات المتحدة الامريكيه، وعبد الله الخال سفير المملكه العربيـهـ السعوديه وي الولايات المتحدة اتقاهيه خاصه بحقوق إستخدام قاعدة الظهران، مكونــه

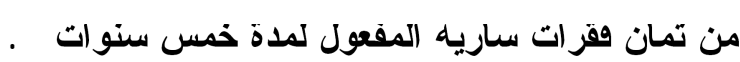
ووي ادار/مارس 1971 اعلتت المملكه العربيه السعوديه انها لن تجــلد إتقافيـه القاعدة الجويه وي الظهرانه والتي كان سوف ينتهي مفعولها بعد سنها وود اعلن الملكك سعود ان السبب الرئيس لها الموفف هو مساندة الولايات المتحدة لإسرائيل19 . ووــي ايار/مايو $197 r$ جددت المملكه رغبتها في عدم التجديد إستجابه إلـى الــراي العسام السعوديه إلا ان الحكومه الامريكيه تمسكت بالقاعدة وحاولت القيام ببعض الإجـراءات الثكليهأكإز الهه ساريه العلم الامريكي من امام مقر القائد العسكريه وروعه على مبنـى المفره وإزاله محطه التلفزيون الامريكي من القاعدة والإكتفاء بتلفزيون شركه ارامكو.

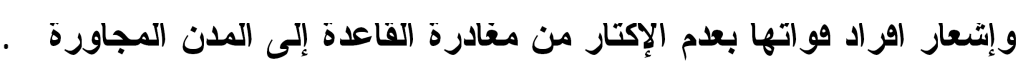
وقد ابلغ ولي العهد السعودي الامير فيصل الرئيس الامريكي جون كيندي (1971" (1971) في رساله جاء ويها "الو كتت مكاتك لبادرت إلى إغلاق قاعدتكم العسكريه في بلانا وعند الحاجه نضعها مجدا في تصرهم"، وقد كاتت القاعدة خلال تلك

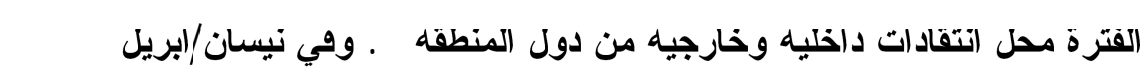
وررث الولايات المتحدة ترك القاعدة وتسليمها للمملكه، ولكنها عادت بعد سته اثهر اتر احداث اليمن "ـ ومند هدا التاريخ يبدو ان الولايات المتحدة بدات تتهج منهجا جليدا وي عمليه التواجد حسب الضرورة او وقى اغطيه وتبريرات. وبالنسبه لتخطيط القاعدة يمكن الاستفادة من الزيارة التي هام بها امسين المميـز السفير العرافي في المملكه العربيه السعوديه عام 1900 إلى القاعدة، التي تقع علـى بعد عشرة كيلومترات من مدينه الظهران وتتشغل القاعدة مساحه تقــلـر ب (ro) مــيلا 
وبالتسبه للقوات المتمركزة ويها فان اول عدد يتمركز ويها من الامريكانه الفي جنــي،

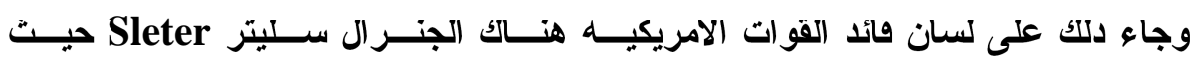
تتمركزالقوة الجويه الامريكيه التانيه، و اول عدد للطائرات هــو (11) طــائرة، وهـي

0 - طائرة من نوع القلعه الطائرة (KM-126).

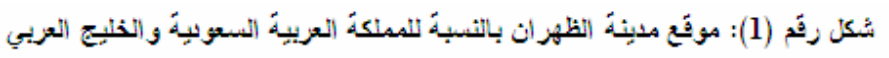

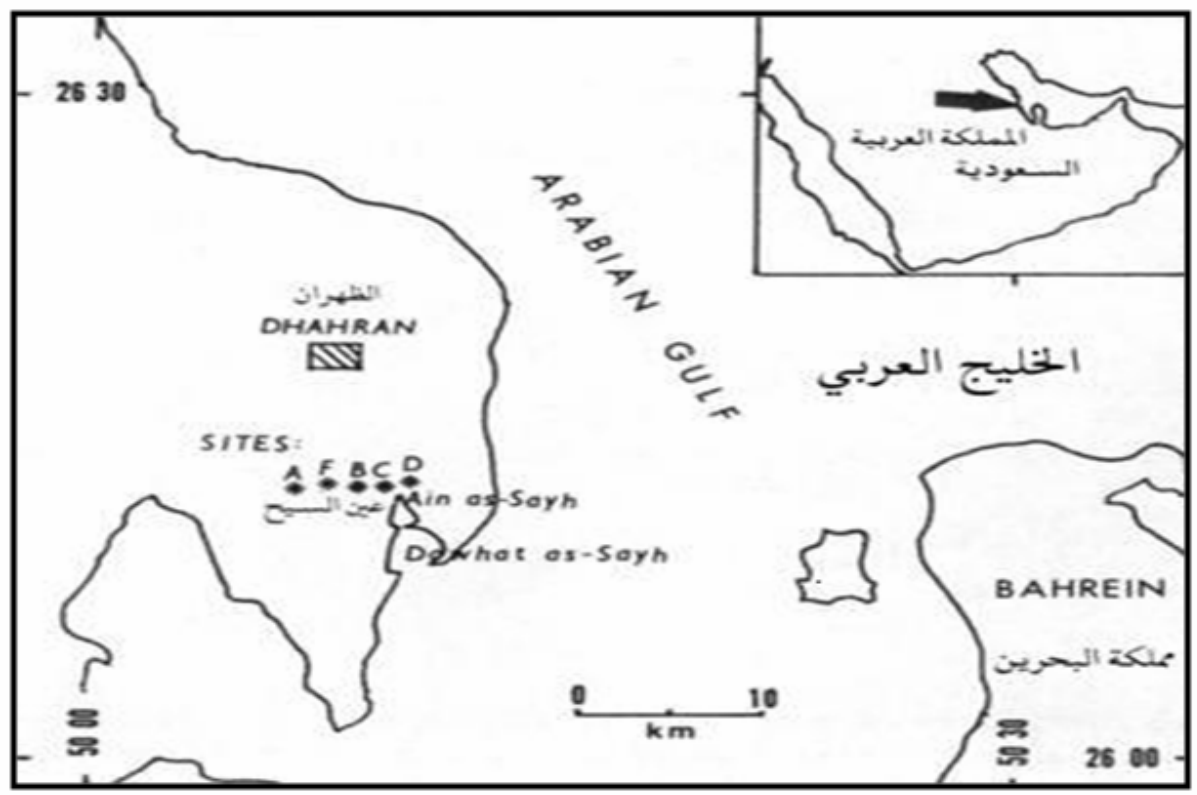


إضافه إلى الطائرات التي تتردد إلى القاعدة من الطائر ات الإستراتيجيه ووادوات القتابـلـل من نوع (B-47) و(B-36) واخرى تحمل هنابل دريه، وتعد واعدة الظهــران اوســع قاعدة في المنطقه الواوعه بين القلبين في الشرق الاصصى، واوربا وشمال الريقيا، فليس هناك فاعدة في هده المنطقه امريكيه او غير امريكيه تماتلها بالـسعله او التجهيـزات،

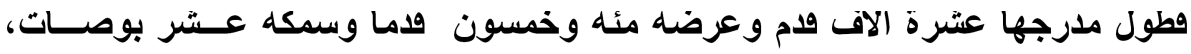
وهناك مدرج اخر يستعل في الاحوال الجويه غير الاعتياديه طوله اول بقليل من تمانيه

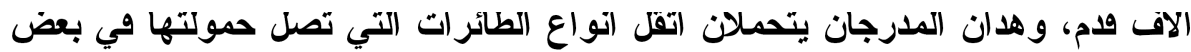

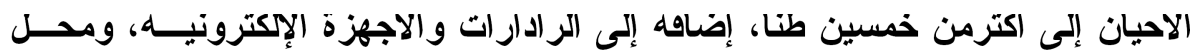
التصليح الطائرات ومعامل لصنع الكتير من هطع الغيار، إضاهه إلى المستودعات وهـي كتيرة جذا ومليئه بالاخيرة و المؤن.

وهناك مستشفى عسكري انقق عليه في تلك الفترة اكتر من تلاته ملايـين دولار،

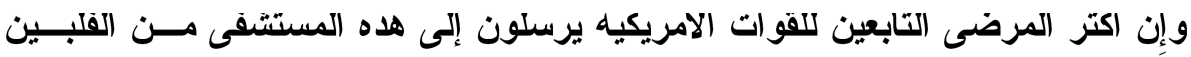
و الهند والباكستان وافغانستان وشمال إريقيا والحبشه و السودان وغيرها من الــدوله

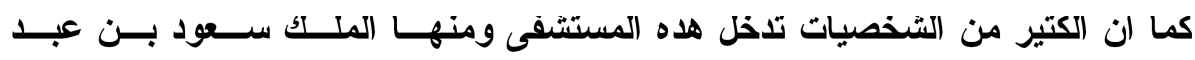
العزيز/190r -1978) و امراد عائته وإن شبكه الإتصالات الموجودة في القاعدة تمكن

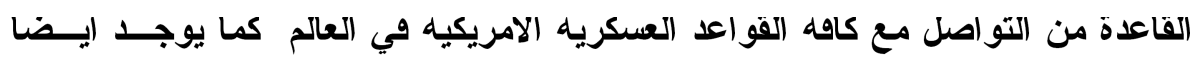
مستودعات للوهود يقع فسم منها تحت الارضه يزاد عليها الاليات الاخرى كالـسيارات

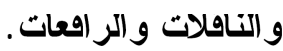

إضافه إلى مساكن الخبراء و الضباط و الفنيين والعسكر و مخزن لبيع جميع اللوازم البيتيه والثخصيه التي يحتاج إليها اوراد القوات وعائلاتهمه وبضائع ها المخزن معفاة من الرسوم الكمركيه، وبيعها محصور بالعسكريين، ويوجد داخل القاعدة كل ما تحتاجه في المدينه، وهناك وسائل ترويه كالسينما وبرك السباحه وساحات اللعب وهـي إمدينـهـ

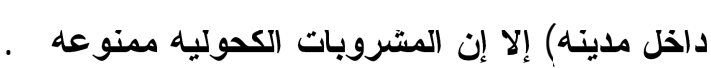

r - دور القاعدة في المنظومه العسكريه لمنطقه الخليج العربي على الرغم من ان دول الخليج كاتت تصرح دوما إن امــن الخـــيج العربــي هـو 
مسؤوليه دول الخليج، وتروض الحمايه الغربيهه إلا ان سير الاحداث اتبت بما لا يقبـل الثكك ان امن الخليج مرهون بالولايات المتحدة الامريكيه، ولا ندري هـلـ دول الخــيج ولاسيما السعوديه مغلوب على امرها ام هي مساله مصالح، وحتى لــو كانــت مسساله مصالح فهي مصالح مرهقه وغير متكافئه. ويكفي ان نستثهل بجزء من وتيقه ارسلتها السقارة الامريكيه وي جدة إلى وزارة الخارجيه الامريكيه بتاريخ MV9 تموز/يوليوني

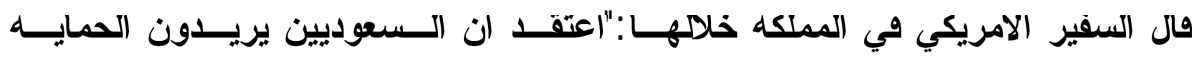
الامريكيه، ولكن مع ظهور هليل... وبالمقابل إدا حصل هجوم من الإتحاد السوفيتي على السعوديين وهم يريدون من وبل الولايات المتحدة المجيء لمساعدتهم على صعيد القـوة والاساليب... غير اتهم مع دلك لا يريدون تواجل عسكري امريكي مباشر في السعوديه او في المنطقه المجاورة، وإدا كان لابد من وجود واعدة او وجود امريكي وهم يفضلون ان يكون دلك وي مكان ما بعيد عن المراى... يرغـب الـسعوديون بتواجـــ امريكـي منفضض حتى لا ينزعج الجيران من دلك... لهـا السبب فإن المتحدتين باسم الحكومسـه السعوديه سيستمرون بالتصريح انهم ضد اي اهتراح علني بان الولايات المتحدة ممكـن او يجب ان تتذخل وي الخليجه وسيتخدون موقفا علنيا باته ليس هناك خطـر حقيقـي"

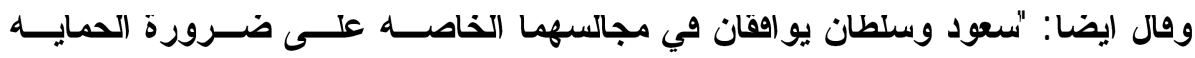

$$
\text { الامريكيه للسعودية'اعب. }
$$

تعد فاعدة الظهران من الهم المنشات الحيويه الممنوحه للولايات المتحدة في منطقه الخليجه وكان لها دور كبير وي كتير من الاحدات التي شهذتها المنطقه، إضــافه إلــى

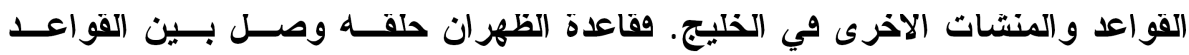
المتواجدة في اورباه والاسطول الامريكي السادس المتواجد في البحر الابيض المتوسط و الشرق الاوصى، وضلا عن الهيتها في حمايه منابع النقط في المملكه والتـي تسسيطر عليها الثركات الاجنبيهه إضافه إلى القوة الجويه الامريكيه الموجودة في هله القاعــدة 
والتي يمكن توجيهها إلى اي نقطه ووي اي ووت

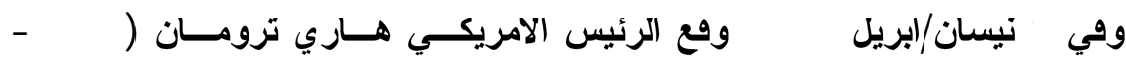
م1901) على هاتون المساعدات الخارجيه، وكاتت السعوديه من ضمن الدول التي شملت التريل بها القانونه وقل اوصت الهيئه المشتركه لرؤساء الاركان بان فاعدة الظهران ســكون مهمه بالنسبه لإدارة العمليات في حال نشوب حرب مع الإتحاد الـسوفيتي، واقترحست

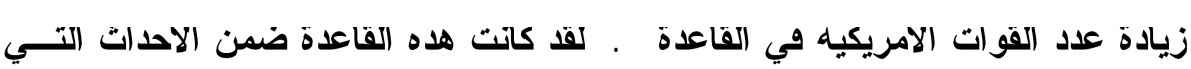

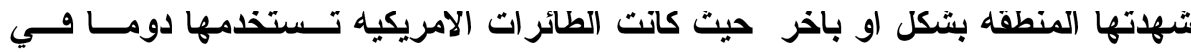
طلعاتها التي تقوم بها في المنطقها ومي نهايه العقد التامن من القرن العـشرين بـــات هده الطلعات تتكتف، وفي اواخر عام I9VA زار سرب من طــائرات (F-15) القاعــدة بلدوة من المملكه العربيه السعوديه واجرى تدريبات وتاليه ووق الاراضي الـسعوديها.

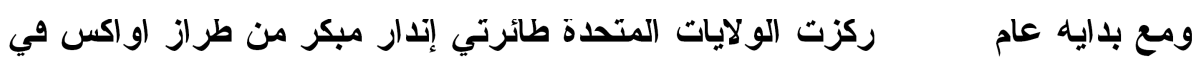

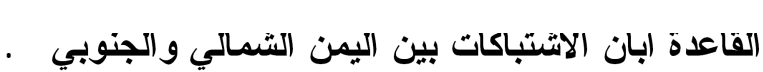
لقد تزامن هلا التواجد ميع بلايات تاسيس الولايات المتحدة لقوة الإتتشار الــسريع في منطقه الخليج العربي، وكاتت تتحرك للحصول على وواعد وتسهيلات لهـه القــوات.

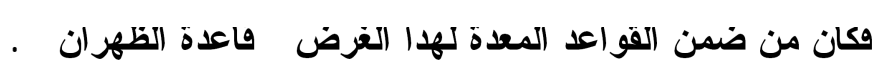
ايضا كان لسقوط الثاه في إيران وإحتلال افغانستان خلال سنه I9V9، دور كبير في تكتيف التواجد الامريكي في المنطقه ووصل إلى القاعدة مجموعات من الكوماندوز الامريكي، وكاتت الطائرة الإستراتيجيه (B-52) تتخد من هاعدة الظهران مستقرا لهـ

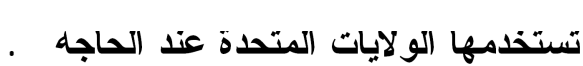
ايضا كاتت القاعدة تستخدم لطلعات طائرات (P-3) للمر اقبه مرة كل شهر تسستمر

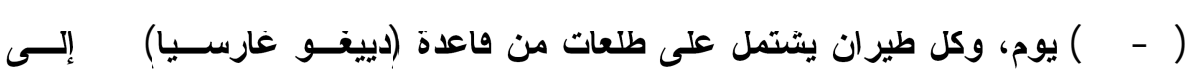
هاعدة الظهران ومن الظهران إلى الظهرانه وتحصل الحكومه السعوديه على المعلومات

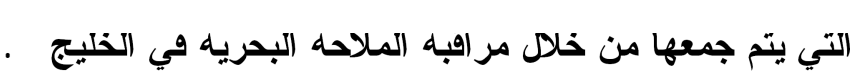

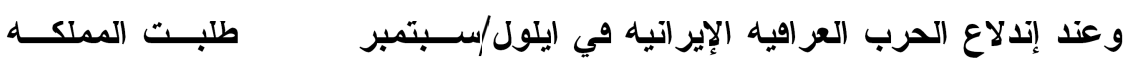

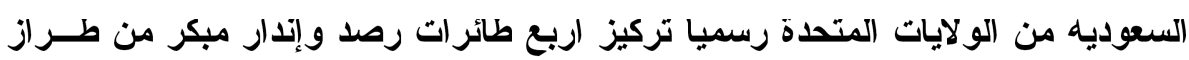




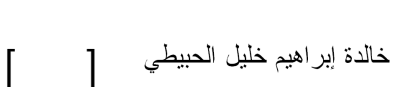

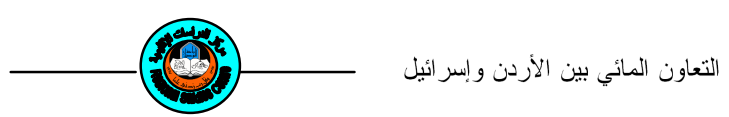

اواكس في هاعدة الظهران. لقد كان الطلب السعودي هلا، يمتـلـل تحــولا جــــيا وــي السياسه السعوديه، وقل كاتت المملكه ومن ضمن خطتها الإعلاميه تؤكل عــى روضـ التواجد الاجنبيه لإا فإن الإعلان عن هله الطائر ات ويبلاو انه كان ضــمن إســراتيجيه معينه تتناسب مي ظروف الحرب. وبعد الطلب السعودي بدات الطائرات الاربع طلعاتهـــ ورصد الوضع العسكري للحرب، كما وصل مع هده الطائرات ( . . ع) عنصر من رجـال سلاح الجو الامريكي مكلقين بمهام الصيانه، بالإضافه إلى طائرتي تموين جوي بالوهود

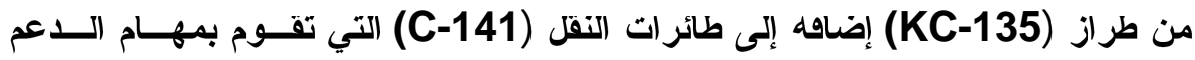
اللوجستي من طر بر.

إن هله الإجراءات تمت على الرغم من علم وجود معاهلدة امنيـهـ رســيه بـين

المملكه و الولايات المتحدة، وخلال هله القترة عمدت المملكه إلى زيادة حجم التسهيلات الممنوحه للولايات المتحدة وي وواعدها الجويه لسلاحي الجو والبحريه الامريكيه، كمـ

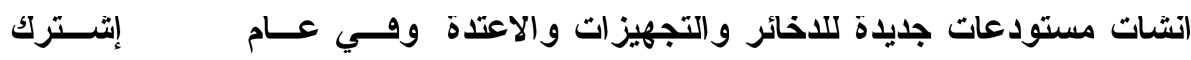

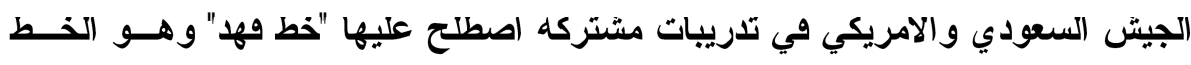

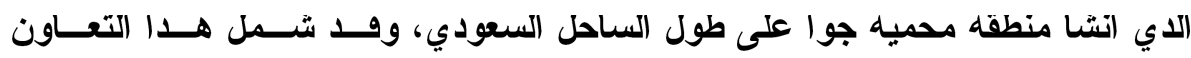

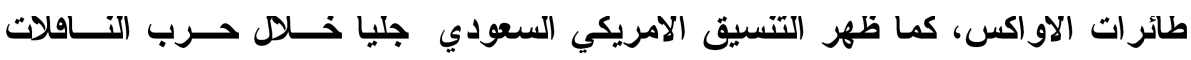
rr (19M- 194V)

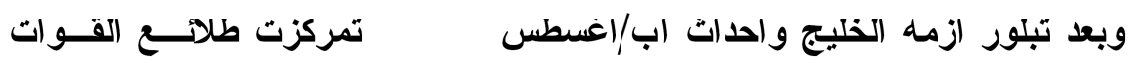

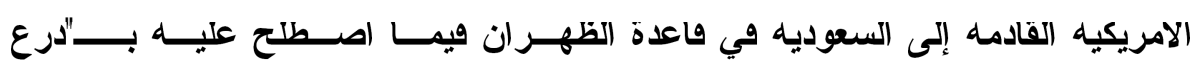
الصحراء"هو مند 7M اب/اغسطس -199 هبط علد كبير من الطائرات الامريكيه وـي القاعدة إستعدادا للحربه وبعد إندلاع حرب الخليج التاتيه كاتت صاعدة الظهران من اهم القواعد العملياتيه للمتحالقينه حيث إستقبلت الطائرات الامريكيه المقاتلهه ومروحيـات

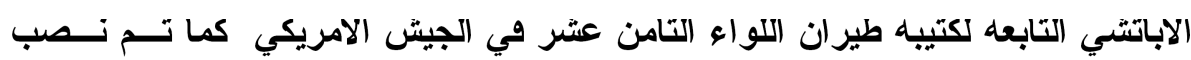

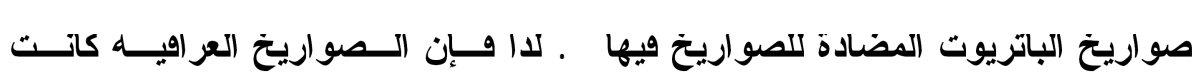


تستهدف هده القاعدة لاهيتها، فكان اخطر هجمات الصواريخ العراقيه خلال الحرب في

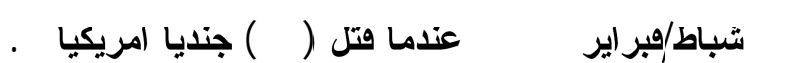
وبعد إنتهاء الحرب لم تكن المملكه تسلط إعلامها عـــى الوجــود الامريكـي فــي

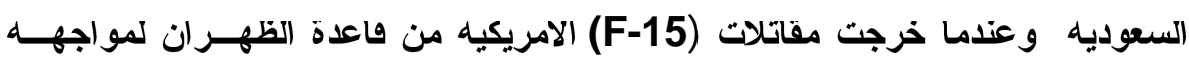
الطائرات العراويه التي تجاوزت خط حظر الطيران المفروض عليهـا، إكتفـت وســائل

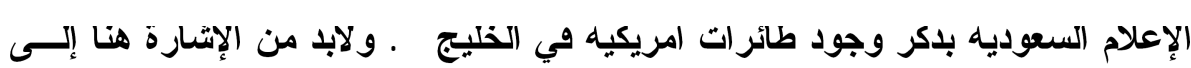
ان الولايات المتحدة إستخدمت وروه العراق كتيرا لاعم وجودها في السعوديه، وعلــى سبيل المتال وي تشرين الاول/اكتوبر ع99 زعمت الولايات المتحدة ان العـراق دوــع

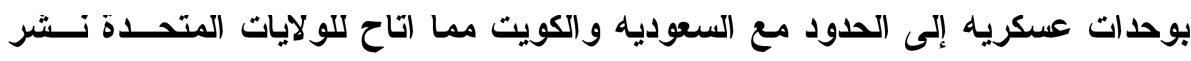

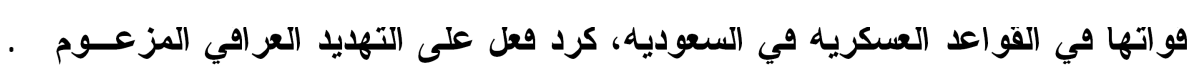

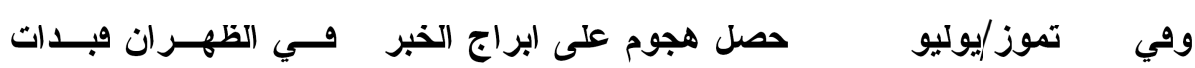

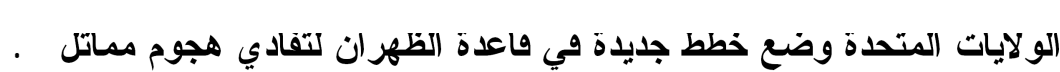

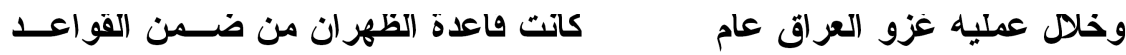
و المنشات التي إستخدمتها الولايات المتحدة في عمليه الغزو على الرغم من التصريحات

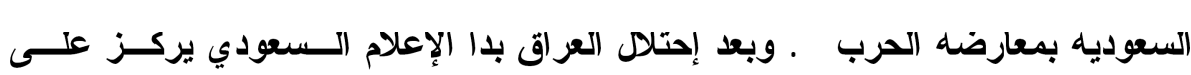
مساله جلاء القوات الامريكيه بالكامل، ولكن المرجح ان نجد ووات امريكيه في القواعد العكريه السعوديه وي حال نشوب اي صراع جديد في المنطقه.

خاتمة

إن إنصال سياسات الدول العربيه وتباينها، جعلها وريسه سهله للاول الكبرى، لاد نجد سقف الممانعه لايها ليس بالمستوى المطلوب، وإلا وما هو تقسير التواجد الامريكي الضخم وي اغلب الدول العربيه. والعالم من حولنا يسير نحو التكتل لمواجهه التحديات،

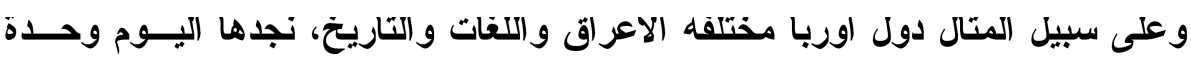

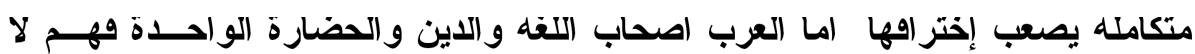
يستطيعون حتى ان يفتحوا اسوار بلا اتهم ويما بينهم فكيف سيفعلون الــدواع المـشترك 

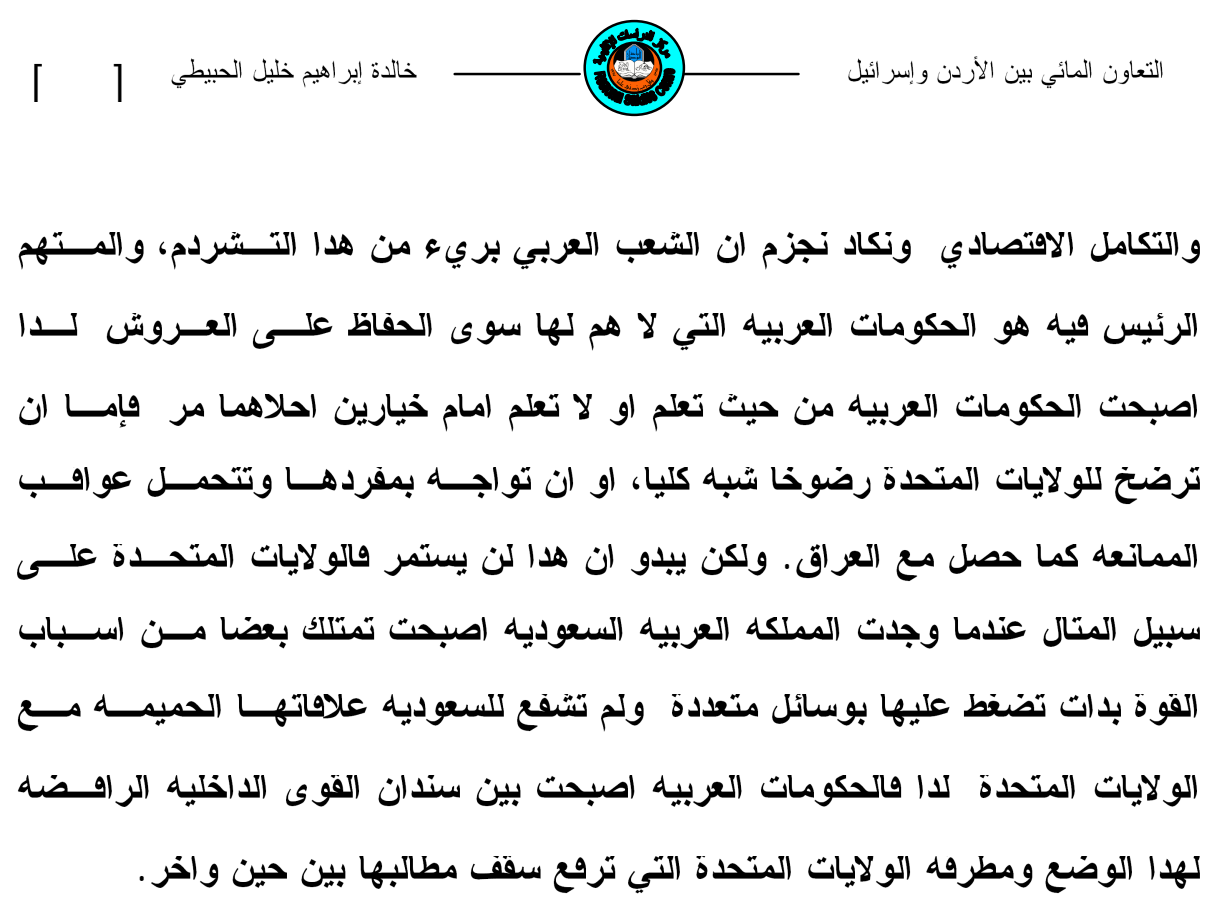

\section{Military Relations Between United States and Arabia Saudi: Al-Dhahran Air Base As A Sample}

Methak K. Jalloud*

\section{Abstract}

U.S. military existence all over the world has become an actual fact especially in the Arab Gulf region. Al- Dhahran air base is considered one of the eldest U.S. bases in the region. But the American existence took new forms after 1962 after it had left it officially. Its existence has become an issue of maneuvering, training and cooperation with Saudi Arabia.

This base has played a significant role in all crises and wars occurred in the area since the second world war till the three Gulf wars. This base was within U.S. strategy and an active part in U.S. tactics in Arab Gulf.

*Assistant lecturer, Department of History and Documentation, Regional Studies Center. 
در اسات إقليمبة ع (9)

] ع ع ع عز الدراسات الإلكيدة

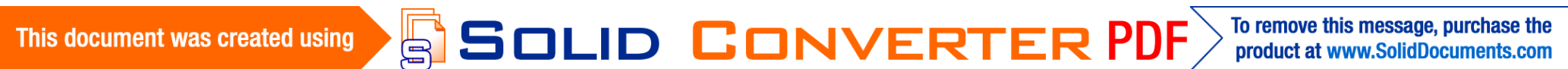


1 موسى زناد، القو اعد العسكرية الأجنبية، مكتبة الفكر العربي للنثر و التوزيع، مطــابع دار القادسـية،

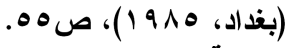

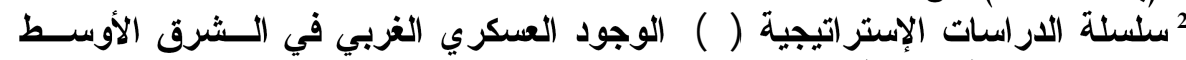

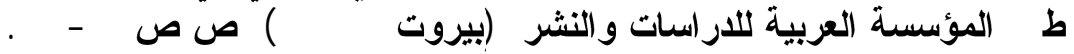

${ }^{3}$ US Army Bases Outside The USA : www.anti-imperialism.net/lai

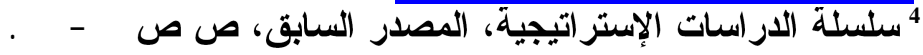

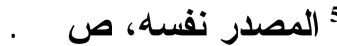
6 أهم القواعد الأمريكية في الخليج لضرب العراق'، معلومات متاحة على موقع منتديات www.majdah.maktoob.com/vb ماجدة:

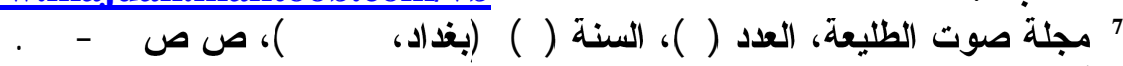

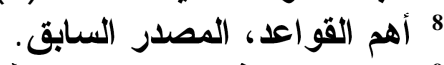
9 جورج لنشوفسكي، الثرق الآوسط في الثؤون العالمية، ترجمة : جعفر خيـاط، دار

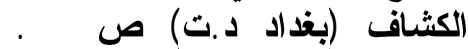

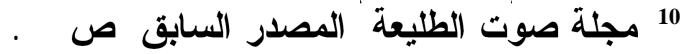
11 تاريخ الاحتلال الأمريكي للجزيرة"، دراسة متاحة على موقع الحرمين: www.alhramain.com

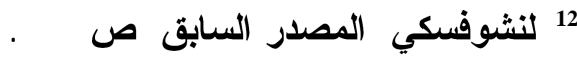

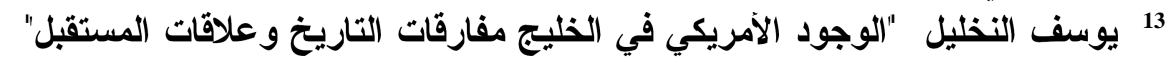

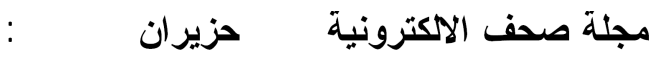

www.sshf.net/gulf-media

$$
14 \text { صوت الطليعة، المصدر السابق، صباع. }
$$

15 "المخطط الأمريكي للسيطرة على منابع النفط"، مركز الشرق العند العربي للار استات www.asharqalarabi.org.uk

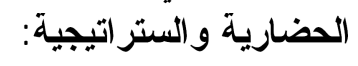
16 تاريخ الاحتلال الأمريكي، المصدر الفئلة السابق.

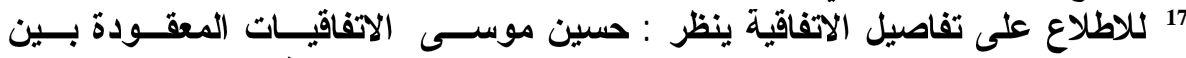

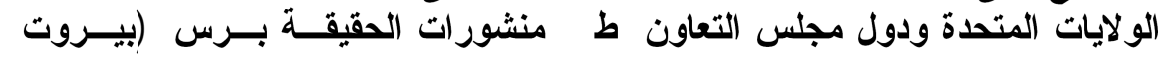

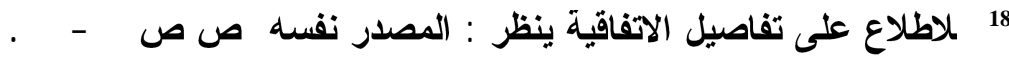
19 سعد الجهني، "مطالب ووعود لم تلحقق"، دراسة متاحة على الفى الموقع: www.saudiaffairs.net 
20 صبري فارس إلهيتي، الخليج العربي : دراسة في الجغرافية الـسباسبة، منـشورات

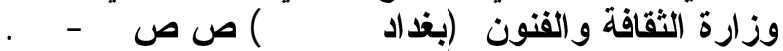

21 آلان غريش، "السعودية أمام التحديات الكبرى'، مقال متاح على الموقع : www.mondiploar.com/juin03

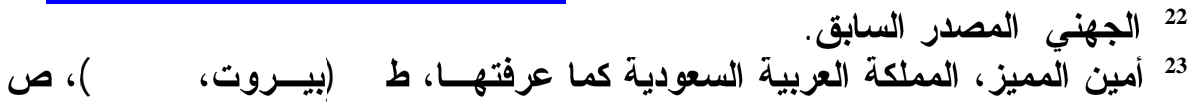

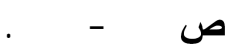

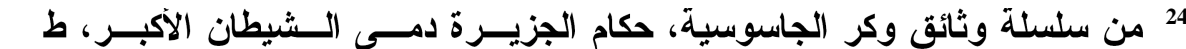

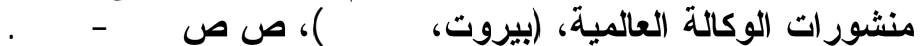

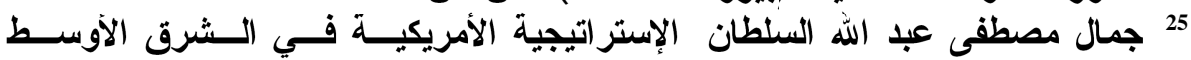

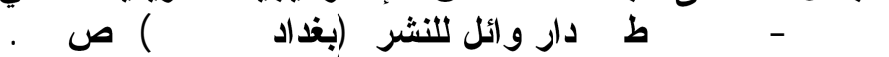

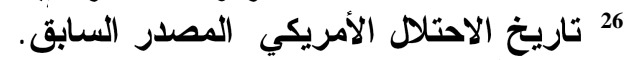

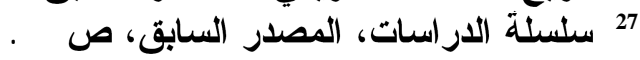

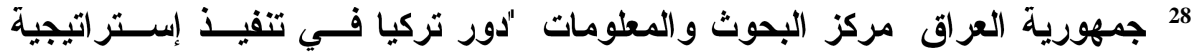

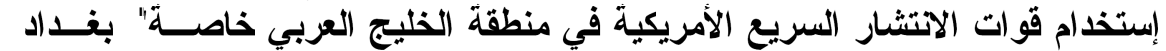
"

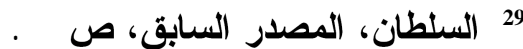

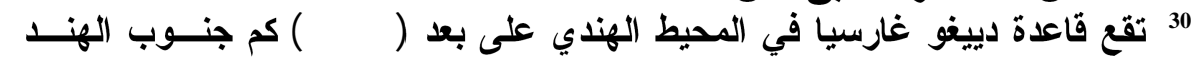

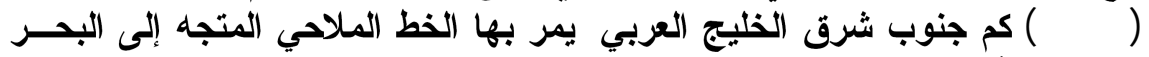

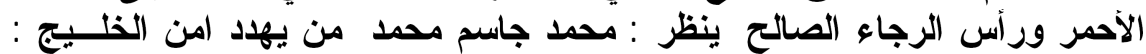

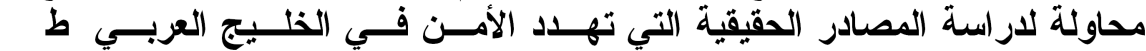

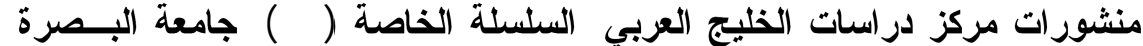

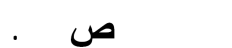

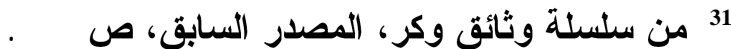

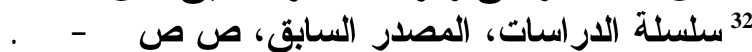

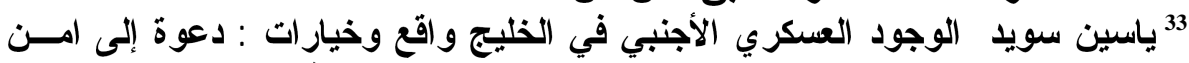

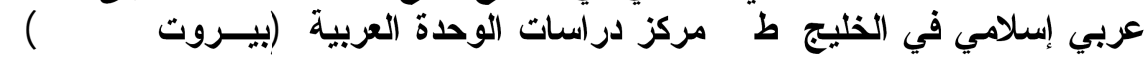

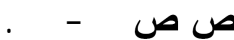

34 "Air Base (KAAB) Dhahran, Saudi Arabia":

www.globalsecurity.org/military;

"Gulf War Photo Sampler Operations Desert Shield and Desert Storm": www.army.mil/cmh/photos/gulf-war 35 "تتابع زمني للعراق في عها صدام'، ملف متاح على الموقع: WWw.bbc.uk/arabic

36 معلومة متاحة على موقع الحوار المتمدن الاكتروني، بتاريخ 1/1/0 - . T: www.alwitwity.friendsofdemocracy.net

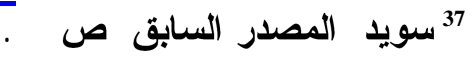

38 للاطلاع على تفاصيل تفجير الخُبر ينظر : 


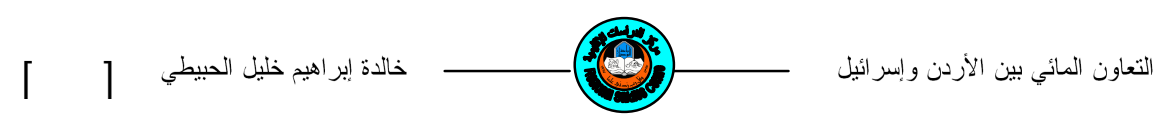

\footnotetext{
"Truck Bombing of USAF Base in Dhahran": www.emergency.com

39 "Sharpening The Eagle's Assessing Air Base Defense":

www.airpower.maxwell.af.mil

40 أهم القواعد، المصدر السابق.
} 